\title{
VELLOZIACEAE DO PARQUE ESTADUAL DE IBITIPOCA, MINAS GERAIS, BRASIL
}

\author{
LAURA MONTSERRAT \& RENATO MELLO-SILVA
}

\author{
Universidade de São Paulo. Instituto de Biociências. Departamento de Botânica. Rua do Matão, 277, \\ edifício Sobre-as-Ondas. 05508-090. São Paulo, SP, Brasil. mellosil@usp.br
}

\begin{abstract}
Velloziaceae from the Ibitipoca State Park, Minas Gerais, Brazil). A survey of Velloziaceae species from the Ibitipoca State Park is presented. The park is located in the Mantiqueira mountain range. Within the park there are several types of vegetation, mostly rocky fields, in which the species of Velloziaceae occur. The family has five genera and approximately 250 species. Two genera and four species occur in the park: Barbacenia flava, Vellozia albiflora, V. crinita and V. intermedia. Key for the genera and species, descriptions and illustrations are presented as well.
\end{abstract}

Key words: Velloziaceae, State Park of Ibitipoca, illustrated flora.

Resumo - (Velloziaceae do Parque Estadual de Ibitipoca, Minas Gerais, Brasil). É apresentado o levantamento das Velloziaceae do Parque Estadual de Ibitipoca. O parque está situado na Serra da Mantiqueira e abriga diversas formações vegetais, principalmente campos rupestres, onde são encontradas as espécies de Velloziaceae. A família conta com cinco gêneros e aproximadamente 250 espécies. No parque ocorrem dois gêneros e quatro espécies: Barbacenia flava, Vellozia albiflora, V. crinita e V. intermedia. São apresentadas chaves de identificação para os gêneros e espécies, descrições e ilustrações.

Palavras chave: Velloziaceae, Parque Estadual de Ibitipoca, Flora ilustrada.

\section{Introdução}

Os tratamentos florísticos são de grande importância no Brasil, que possui uma das floras mais ricas do planeta (Forzza et al. 2012). Entretanto, o número de taxonomistas é ainda insuficiente no país e as coleções não apresentam uma boa amostragem da flora, tornando imprescindível e urgente a realização de programas de coleta e de conservação visando a compilação de um tratamento completo das espécies da flora brasileira (Wanderley et al. 2005). Além disso, Floras são úteis na identificação de espécies, na facilitação de estudos taxonômicos mais aprofundados e como base para trabalhos em áreas correlatas, além da formação de recursos humanos (Mello-Silva 2005b). O Parque Estadual de Ibitipoca é uma das regiões do Brasil que apresenta grande necessidade e urgência da realização de levantamentos florísticos, e é considerado de importância prioritária para a conservação da fauna e flora (Costa et al. 1998). Além da riqueza de espécies que abriga, o parque representa atualmente uma pequena amostra da vegetação original da região, já que a maior parte das áreas que compõe o Planalto de Andrelândia e a Serra da Mantiqueira teve sua vegetação original substituída por pastos e culturas (Rodela 2000).

A elaboração de levantamentos florísticos na região, além de registrar a riqueza de espécies de uma região, pode servir de base para políticas de preservação dessas áreas e de sua flora, com destaque para as eventuais espécies endêmicas. Além disso, estas ações e o conhecimento da biodiversidade de uma área são importantes medidas de proteção, principalmente em locais onde é grande o número de visitantes, com consequente pressão sobre a fauna e a flora locais (Ladeira et al. 2007, Costa et al. 1998).

Dentre as famílias que compõe a flora do Parque Estadual de Ibitipoca está Velloziaceae, família essencialmente anfiatlântica, com cinco gêneros e aproximadamente 250 espécies. A maioria das espécies é neotropical (Barbacenia, Barbaceniopsis e Vellozia), cerca de 30 delas ocorrem na África, três em Madagascar, uma na península arábica (Xerophyta), e uma na China (Acanthochlamys) (Mello-Silva 2005a, Mello-Silva et al. 2011). A grande maioria das espécies de Velloziaceae encontra-se no planalto central brasileiro. Minas Gerais é o estado que concentra o maior número de espécies, com cerca de 170, cuja maioria concentra-se na região que compreende a Serra do Cipó e o Planalto de Diamantina (Mello-Silva 1995a, Mello-Silva 2010). Apesar dessa alta diversidade no Brasil, existem poucos trabalhos florísticos com Velloziaceae. O único de cunho estadual é do Estado de São Paulo (Mello-Silva 2005a); e os demais são de cunho regional, como Grão-Mogol, MG (Mello-Silva 2009) e Pico das Almas, BA (Mello-Silva 1995b). Este trabalho procura inserir-se no contexto de melhor conhecimento da família Velloziaceae e da Flora do Parque Estadual de Ibitipoca, da qual alguns tratamentos florísticos têm sido realizados recentemente (e.g., Chiavegatto \& Baumgratz 2007, Medeiros \& Guimarães 2007, Menini-Neto et al. 2007, Milward-de-Azevedo 2007, Monguilhott \& Mello-Silva 2009). 


\section{Material e métodos}

O Parque Estadual de Ibitipoca está inserido na Serra de lbitipoca, localizada no sudeste de Minas Gerais, nos municípios de Lima Duarte e Santa Rita do Ibitipoca $\left(21^{\circ} 40^{\prime} 15^{\prime \prime}\right.$ a $21^{\circ} 43^{\prime} 30^{\prime \prime S}$ e $43^{\circ} 52^{\prime} 35^{\prime \prime}$ a $\left.43^{\circ} 54^{\prime} 15^{\prime \prime} \mathrm{W}\right)$, que faz parte do Complexo da Mantiqueira e do Planalto de Andrelândia (Rodela 2000). Possui uma área de 1.488 ha e altitudes variando de 1000 a 1784 m (Rodela \& Tarifa 2002). São predominantes na região os campos, que ocupam cerca de $45 \%$ do total da área do parque, além de formações savânicas e florestais (Andrade \& Souza 1995, Dias et al. 2002).

A análise do material foi realizada com o auxílio de estereomicroscópio com câmara-clara acoplada de coleções depositadas nos herbários citados (siglas segundo Thiers 2010) e de materiais fixados provenientes de expedições de coleta realizadas em janeiro e dezembro de 2010. O hábito, cores, distribuição, hábitat e outras características não mensuráveis foram baseadas nas informações das etiquetas das exsicatas, da literatura e de anotações de campo.

\section{Resultados e discussão}

Velloziaceae conta com cinco gêneros e aproximadamente 250 espécies. No parque ocorrem dois gêneros e quatro espécies: Barbacenia flava, Vellozia albiflora, V. crinita e $V$. intermedia.

Chave para os gêneros

1. Corona presente, laminar; estames 6 , filetes ausentes, anteras inseridas nos lobos da corona 1. Barbacenia 2. Vellozia

\section{Barbacenia Vand.}

Ervas ou arbustos; caule 3 a $80 \mathrm{~cm}$ compr.; folhas trísticas ou espirotrísticas, lâmina foliar persistente, sem linha de abscisão, as velhas marcescentes e reflexas; flores perfeitas; hipanto pouco a muito mais longo que o ovário; corona laminar, com seis lobos; estames 6, anteras dorsifixas ou basifixas, sésseis, inseridas na corona ou no ápice do hipanto, introrsas, 2-loculares, grãos de pólen em mônades; estigmas 3, apicais, subapicais ou laterais, distintos, confluentes ou não, verticais, lineares ou elípticos. Cápsula loculicida ou deiscente por fendas apicais sobre o lóculo ou entre as costelas. Sementes numerosas.

Barbacenia tem quase 100 espécies exclusivamente neotropicais. A maioria ocorre no Planalto Central do Brasil, principalmente na Cadeia do Espinhaço (Mello-Silva 2005a, Mello-Silva 2010). No Parque Estadual de Ibitipoca ocorre uma espécie.

1.1. Barbacenia flava Mart. ex Schult. \& Schult.f., Syst. veg. 7(1): 286. 1829.

Fig. 1

Plantas solitárias ou cespitosas. Caule simples, 3,5-30 x 0,6-3,0 cm. Folhas espirotrísticas, Lâmina foliar reta, linear-lanceolada, $13-24 \mathrm{~cm} \times 5-13 \mathrm{~mm}$, glabra, margens e nervura central na face abaxial ciliadas, tricomas mais longos em direção à base; linha de abcisão ausente, as lâminas velhas reflexas e marcescentes. Flores 1-3; pedicelo 11-26 cm compr., densamente coberto de emergências glandulares em direção ao ápice. Hipanto obcônico, trígono, 1,8-3,8 $\mathrm{cm} \times 5-7 \mathrm{~mm}$, secção fundida ao ovário $0,8-1,9 \mathrm{~cm} \times 4$ -
$5 \mathrm{~mm}$ no ápice, densamente coberta de emergências glandulares, verde, tubo do hipanto1-2 cm x 6-7 mm, subdensamente coberto de emergências glandulares, amarelo. Sépalas e pétalas lanceoladas, $1,2-2 \mathrm{~cm} x$ 2,5-7 mm, amarelas; sépalas esparsamente cobertas por emergências glandulares na face abaxial, face adaxial lisa; pétalas lisas exceto por emergências glandulares sobre a nervura central na face abaxial. Lobos da corona oblongos, 6-7 x 2-3 mm, amarelos, bilobulados no ápice, lóbulos triangulares, 1,5-2 mm compr. Estames 6; anteras 1,1-1,3 cm compr., amarelas, sésseis, dorsifixas, inseridas na região central dos lobos da corona. Estilete 1-1,2 cm compr., amarelo, estigmas verticais, fundidos no ápice, 4-5 mm compr., amarelos. Cápsula 3-3,7 x 1,2-1,4 cm, elipsoide, trígona, loculicida, densamente coberta de emergências glandulares. Sementes numerosas, castanho-escuras.

Material examinado: MINAS GERAIS: Lima Duarte, Parque Estadual de Ibitipoca, 14.V.1970 (fl), Krieger s.n. (CESJ 8590, SPF); 17.XII.1986 (fl), Andrade 848 (BHCB, SPF); 9.IV.1987 (fl), Sousa 10924 (BHCB, SPF); 25.VI.1987 (fl), Andrade 984 (BHCB, SPF); Lombada, 20.VI.1991 (fl), Pires s.n. (CESJ 24771, SPF); trilha para os Três Arcos, 27.VII.1991 (fl), Eiterer s.n. (CESJ 24880, SPF); campo rupestre acima da Prainha, 3.IV.1993 (fl), Ferreira 2 (CESJ, SPF); 2142'87"S 4353'79"W, 8.XII.1998 (fl), Martinelli 15287 (RB, SPF); trilha para a Lombada, 8.II.2001 (fl), Forzza 1773 (CESJ, SPF); atrás da lanchonete, $21^{\circ} 42^{\prime} 32^{\prime \prime S} 43^{\circ} 53^{\prime} 41^{\prime \prime} \mathrm{W}$, 4.II.2004 (fl), Forzza 2644 (RB, SPF); trilha para o Morro da Cruz, 30.XI.2004 (fl), Bezerra 49 (SPF); trilha para a Lombada, contrafortes abaixo da Gruta do Cruzeiro, campo entre rochas baixas, $21^{\circ} 42^{\prime} 02,1^{\prime \prime S} 43^{\circ} 53^{\prime} 57,9 \mathrm{~W}$ ", 26.I.2010 (fl), Mello-Silva 3248 (K, NY, RB, SPF); trilha para a Cachoeira

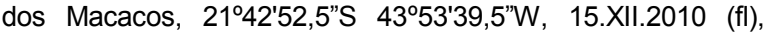
Montserrat 1 (SPF); trilha para o Pico do Pião, 21042'11,7"S 435' 13,8”W, 16.XII.2010 (fr), Montserrat 5 (SPF). 


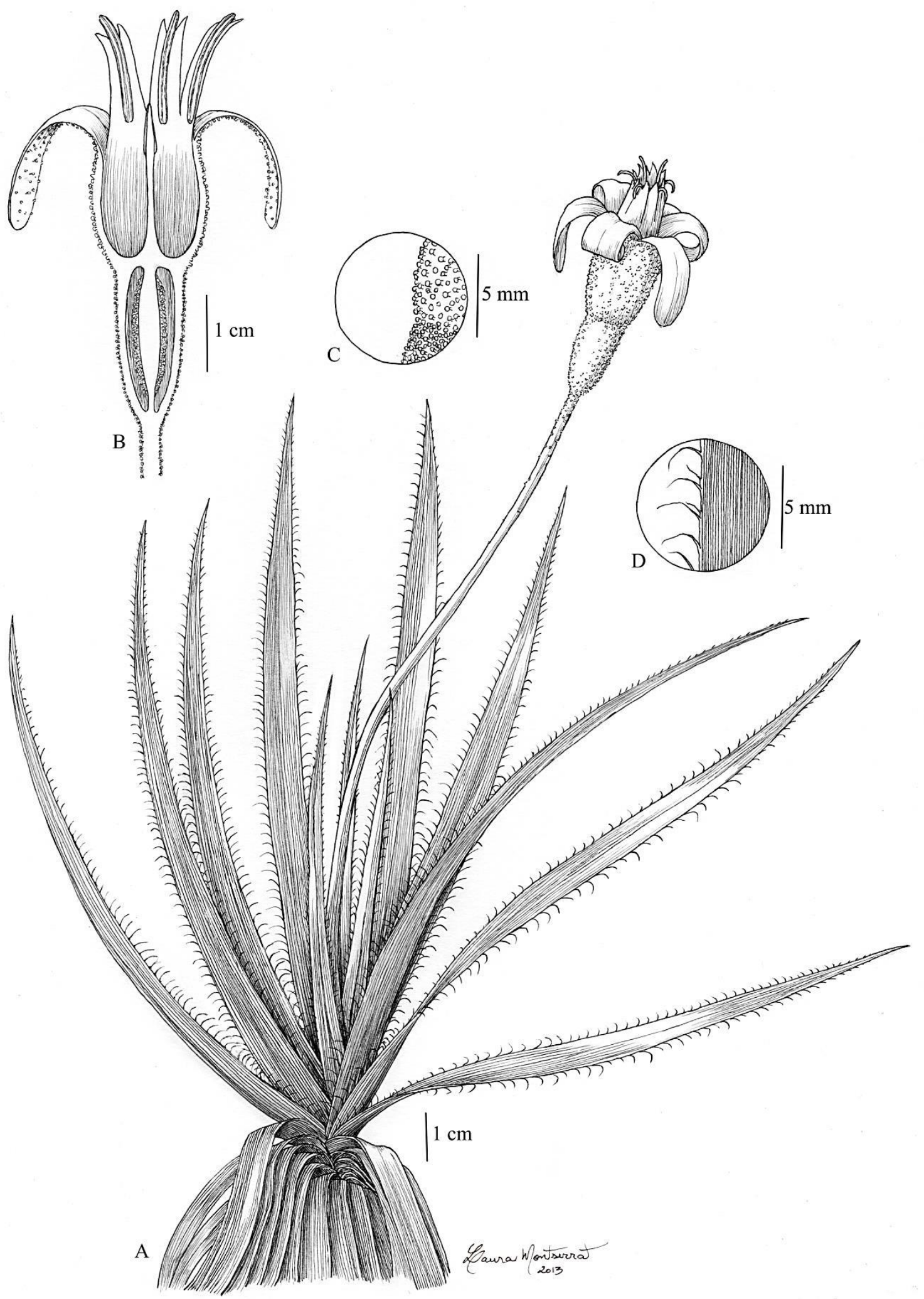

Fig. 1 - Barbacenia flava: A. hábito com flor; B. flor em corte longitudinal; C. detalhe do hipanto, na região entre o ovário e o tubo, mostrando as emergências glandulosas; D. detalhe da margem da lâmina foliar, mostrando tricomas (Mello-Silva 3248 ). 
Barbacenia flava ocorre em duas áreas mais ou menos distintas de Minas Gerais, do Planalto de Diamantina à Serra do Caraça, e em áreas de arenito da Mantiqueira, da Serra da Bocaina, em Lavras, à Serra de Ibitipoca, em Lima Duarte.

No parque, $B$. flava é a única espécie de Velloziaceae com perianto amarelo e tubo do hipanto desenvolvido. Outra característica marcante da espécie é a presença da corona laminar, uma sinapomorfia do gênero Barbacenia (Mello-Silva 2005, Mello-Silva et al. 2011). Pode ser encontrada por todas as regiões de campo rupestre do parque. Foi coletada com flores de novembro a julho e com frutos em janeiro.

\section{Vellozia Vand.}

Ervas ou arbustos; caule $3 \mathrm{~cm}$ a $6 \mathrm{~m}$ compr.; folhas trísticas ou espirotrísticas, lâmina foliar ou cedo caduca por linha de abscisão ou persistente, sem linha de abscisão, as velhas marcescentes e reflexas; flores perfeitas; hipanto menor, igual ou muito maior que 0 ovário; corona fimbriada ou ausente, estames 6,9 ou mais, em falanges de 2 ou mais; filetes livres, anteras basifixas, latrorsas ou látero-introrsas, 4-loculares, amarelas ou amarelo-pálidas, grãos de pólen em tétrades ou raramente em políades ( $V$. andina $\mathrm{lbisch}$, R.Vásquez \& Nowicki); estigmas 3, apicais, distintos, confluentes, horizontais ou quase, orbiculares. Cápsula loculicida ou deiscente por fendas apicais sobre o lóculo ou por dissolução das paredes entre as costelas. Sementes numerosas.

Vellozia tem pouco mais de 100 espécies, exclusivamente neotropicais; como em Barbacenia, a maioria ocorre no planalto Central do Brasil, principalmente na Cadeia do Espinhaço (Mello-Silva 2005a, Mello-Silva 2010). No Parque Estadual de Ibitipoca são encontradas três espécies.

\section{Chave para as espécies de Vellozia}

1. Folhas espirotrísticas, lâminas foliares velhas marcescentes e reflexas, flores 1-6 por ramo, estames Folhas trísticas, lâminas foliares decíduas por linha de abscisão, flor 1 por ramo, estames 12 ou 18 ,

1'. Folhas trísticas,
corona ausente.

2. Bainhas foliares laceradas, margens foliares serruladas, espessadas, estames $12 \ldots \ldots \ldots \ldots$
2'. Bainhas foliares não laceradas, margens foliares ciliadas, não espessadas, estames 18

2. Bainhas foliares laceradas, margens foliares serruladas, espessadas, estames $12 \ldots \ldots \ldots \ldots . . . . . .$.
2'. Bainhas foliares não laceradas, margens foliares ciliadas, não espessadas, estames 18

2.3. V. intermedia

2.1. V. albiflora

2.2. V. crinita

2.1. Vellozia albiflora Pohl, PI. bras. icon. descr. 1: 121.1828.

Fig. 2

Plantas cespitosas. Caule ramificado, 4-8 x 1$1,5 \mathrm{~cm}$. Folhas trísticas; lâmina foliar arqueada, linearlanceolada, $14-30 \mathrm{~cm}$ × 3-8 mm, glabra, margens espessadas e nervura central na face abaxial serreadas, linha de abscisão presente, a lâmina cedo decídua e as bainhas foliares cedo laceradas. Flor solitária; pedicelo 4-11,5 cm compr., 7-19 cm compr., esparsamente coberto de emergências, algumas glandulares, no terço distal. Hipanto 5-12 x 3-5 mm, globular, verde, às vezes verde-arroxeado, densamente coberto de emergências subuladas ou glandulares. Sépalas e pétalas oval-lanceoladas, 3,3$6,8 \times 0,9-1,3 \mathrm{~cm}$, roxas, às vezes brancas nos dois terços inferiores ou completamente brancas, lisas exceto por emergências glandulares sobre a nervura central na face abaxial. Corona ausente. Estames 12, filetes 8-10 mm compr., anteras 2,5-3,0 cm compr., amarelas, basifixas. Estilete 2,8-4,5 cm compr., alvacento, estigma trilobo-peltado, 2-4 mm diâm., amarelo. Cápsula 14-18 x 10-12 mm, globular, loculicida, densamente coberta por emergências, algumas glandulares. Sementes numerosas, castanhas.
Material examinado: MINAS GERAIS: Lima Duarte, Parque Estadual de Ibitipoca, 20.XI.1986 (fl), Andrade 835b (BHCB, SPF); 6.X.1987 (fl), Andrade 1027 (BHCB, SPF); paredão acima da Pedra Quadrada, 2.X.1993 (fl), Ferreira 10 (CESJ, SPF); trilha Portaria - Gruta das Bromélias, 13.XI.1993 (fl), Ferreira 13 (CESJ, SPF); canyon do Córrego do Carneiro, 13.XI.1993 (fl) Ferreira 14 (CESJ, SPF); Ponte de Pedra, 2142'S 435'W, 28.X.2004 (fl), Forzza 3592 (RB, SPF); proximidades da lanchonete, 21\%42' S 4353'W, 23.XI.2004 (fl, fr), Forzza 3667 (RB, SPF); campo na base do Pião, 2142'S 435'W, 18.I.2005 (fr), Forzza 3932 (RB, SPF); trilha da Prainha, 2140'S 435'W, 26.V.2005 (fr), Forzza 3985 (RB, SPF); trilha para a Cachoeira dos

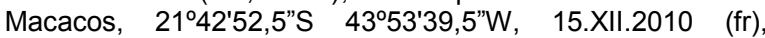
Montserrat 2 (SPF).

Vellozia albiflora é uma das espécies de mais ampla distribuição em Velloziaceae, ocorrendo em toda a Cadeia do Espinhaço de Minas Gerais, nas áreas de arenito da Cadeia da Mantiqueira, em Minas Gerais, e nos afloramentos gnáissicos da Serra dos Órgãos, Rio de Janeiro, e das montanhas do Espírito Santo (Mello-Silva 1995a).

No parque, $V$. albiflora pode ser diferenciada das outras duas espécies de Vellozia pelo caule com bainhas laceradas e pelo androceu dodecandro. O número de estames de $V$. albiflora varia de 12 a 24 , sendo menor nas populações dos extremos norte e sul de sua distribuição, Grão-Mogol, MG, e Petrópolis, RJ 


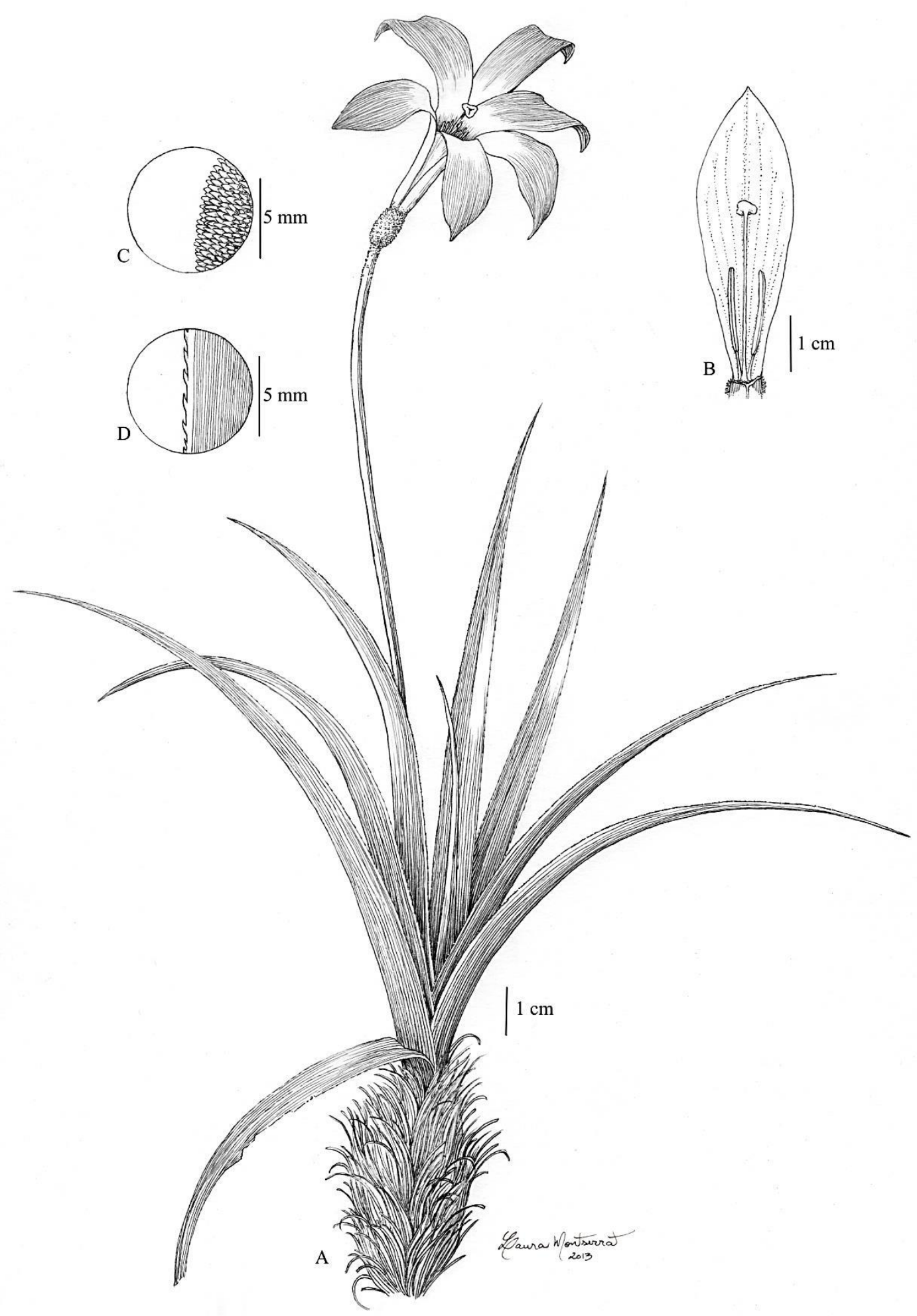

Fig. 2 - Vellozia albiflora: A. hábito com flor; B. detalhe da flor em corte longitudinal, mostrando uma pétala em vista frontal, dois estames e ápice do ovário com estilete e estigma; C. detalhe do hipanto, na região do ovário, mostrando as emergências não glandulares; D. detalhe da margem da lâmina foliar, mostrando emergências serreadas (Montserrat 2). 
(Mello-Silva 1995a). As populações de Ibitipoca têm em comum com as vizinhas de Rio Preto e da Serra do Caraça a presença de emergências glandulares no hipanto, quando a maioria restante das populações as têm sempre subuladas (Mello-Silva 1995a). No parque é encontrada em campos rupestres, ocorrendo em grandes populações formando touceiras nos afloramentos rochosos. Encontrada com flores em outubro e novembro e com frutos de novembro a maio.

2.2. Vellozia crinita Goethart \& Henrard in Henrard, Blumea 2: 368. 1937.

Fig. 3

Plantas cespitosas. Caule ramificado, 8-40 x 1$1,8 \mathrm{~cm}$. Folhas trísticas; lâmina foliar arqueada, linearlanceolada, 11-21 cm x 5-8 mm, glabra, margens e nervura central na face abaxial ciliadas, às vezes serreadas próximo ao ápice, os tricomas mais longos em direção à base; linha de abscisão presente, a lâmina cedo decídua e as bainhas foliares permanecendo inteiras. Flor solitária; pedicelo 4-11,5 cm compr., esparsamente coberto de emergências glandulares em direção ao ápice. Hipanto 7-12 x 4-8 $\mathrm{mm}$, globular, verde, às vezes verde-arroxeado, densamente coberto de emergências glandulares. Sépalas e pétalas oval-lanceoladas, roxas, raramente brancas; sépalas 3,2-5,3 x 0,8-1,3 cm, lisas exceto por emergências glandulares sobre a nervura central na face abaxial; pétalas 3,2-5,3 x 1,1-1,5 cm, lisas. Corona ausente. Estames 18, filetes 7-9 mm compr., anteras 1,4-1,9 cm compr., amarelas, basifixas. Estilete 2,7-3,5 cm compr., alvacento, estigma trilobopeltado, 3-4 mm diâm., amarelo. Cápsula 12-13 x 6-8 $\mathrm{mm}$, globular, loculicida, densamente coberta por emergências glandulares. Sementes numerosas, castanho-escuras.

Material examinado: MINAS GERAIS: Lima Duarte, Parque Estadual de Ibitipoca, 19.II.1987 (fl), Andrade 912 (BHCB, SPF); Cachoeira dos Macacos, 2.X.1993 (fr), Ferreira 9 (CESJ, SPF); borda do paredão acima da Pedra Quadrada, 2.X.1993 (fr, fl), Ferreira 12 (CESJ, SPF); Ponte de Pedra, 12.III.1994 (fl), Forzza s.n. (CESJ 27322, SPF); vale do Rio

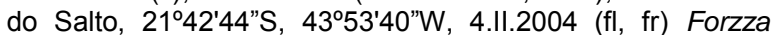
2650 (RB, SPF); entre a Ponte de Pedra e o camping, 30.III.2004 (fl, fr), Forzza 3286 (RB, SPF); trilha para a Lombada, contrafortes abaixo da Gruta do Cruzeiro, campo entre rochas baixas, $2^{\circ} 42^{\prime} 02,1^{\prime \prime} \mathrm{S} 43^{\circ} 53^{\prime} 57,9^{\prime \prime} \mathrm{W}, 26 . \mathrm{I} .2010$ (fl, fr), Mello-Silva 3249 (CESJ, K, NY, RB, SPF, US, W); Prainha das Elfas, 21042'29,7"S 4353'37,8"W, 16.XII.2010 (fr), Montserrat 4 (SPF).

Além de Ibitipoca, Vellozia crinita ocorre ainda a $70 \mathrm{~km}$ nor-noroeste, nas serras do Lenheiro e de São José, em São João del Rei e Tiradentes.

No parque, $V$. crinita pode ser diferenciada das outras duas espécies de Vellozia pelos caules ramificados e longos, cobertos por bainhas inteiras, e folhas e flores usualmente de menores dimensões. Também pode ser diferenciada pelo androceu com 18 estames. Ocorre nos campos rupestres, geralmente, de maiores altitudes, normalmente em formações rochosas. É encontrada com flores e frutos de outubro a março.

2.3. Vellozia intermedia Seub. in Mart., FI. bras. 3(1): 78.1847

Fig. 4

Plantas solitárias ou cespitosas. Caule simples, $5-15 \times 1,5-3 \mathrm{~cm}$. Folhas espirotrísticas, retas; lâmina linear-lanceolada, 5-50 x 1,2-1,7 cm, glabra, margens e nervura central na face abaxial serreadas, linha de abscisão ausente, as folhas velhas marcescentes e reflexas. Flores 1-6; pedicelo 10-22,5 cm compr., esparsamente coberto por emergências glandulares em direção ao ápice. Hipanto 1-1,5 cm x 6-13 mm, obovoide-trígono, verde a violeta escuro, densamente coberto por emergências glandulares. Sépalas e pétalas oval-lanceoladas, 4,4-7 x 1,6-3,2 cm, roxas, à vezes esbranquiçadas na região proximal, lisas. Corona fimbriada, conspícua, branca. Estames 26-28; filetes ca. $8 \mathrm{~mm}$ compr., brancos; anteras 1,2-1,7 cm compr., amarelas, basifixas. Estilete ca. $3,2 \mathrm{~cm}$ compr., branco, estigma trilobo-peltado, ca. $3 \mathrm{~mm}$ diâm., amarelo. Cápsula 1,2-1,7 x 1,2-1,4 cm, obovoide-trígona, poricida, densamente coberta por emergências glandulares. Sementes numerosas, castanhas.

Material examinado: MINAS GERAIS: Lima Duarte, Parque Estadual de Ibitipoca, 5.V.1987 (fl), Andrade 957 (BHCB, SPF); camping, descida para a Prainha, 15.V.1993 (fl), Ferreira 7 (CESJ, SPF); trilha para a Lombada, contrafortes abaixo da Gruta do Cruzeiro, campo entre

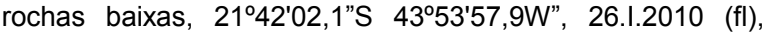
Mello-Silva 3246 (SPF); trilha para o Pico do Pião, cerca de

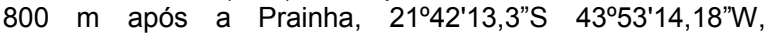
27.I.2010 (fl), Mello-Silva 3262 (CESJ, K, NY, RB, SPF); trilha para o Pico do Pião, $21^{\circ} 42^{\prime} 11,9^{\prime \prime} S 43^{\circ} 53^{\prime} 13,8^{\prime \prime W}, 16 . X I I .2010$ (fr), Montserrat 3 (SPF); proximidades da lanchonete, $21^{\circ} 42^{\prime} 32,7^{\prime \prime S} 43^{\circ} 53^{\prime} 39,2$ "W, 16.XII.2010 (fr), Montserrat 6 (SPF).

Vellozia intermedia, como Barbacenia flava, ocorre disjuntamente em duas áreas de Minas Gerais, ao centro, no Planalto de Diamantina e Serra do Cabral, e no sul, em lbitipoca e serras adjacentes, passando por Lavras, até Capitólio e Serra da Canastra.

No parque, $V$. intermedia pode ser diferenciada das demais espécies de Vellozia pela filotaxia espirotrística, folhas marcescentes e reflexas, e a frequente presença de mais de uma flor por ramo, chegando a seis. Toda a planta em geral tem dimensões maiores do que as demais espécies do gênero do parque. Também pode ser diferenciada pela corona, com franjas abundantes, delimitando uma câmara nectarífera, e pelo androceu com 26 a 28 estames. Muitas vezes suas flores possuem perianto alvo na porção proximal. Pode ser encontrada em locais de campo rupestre. Foi coletada com flores em janeiro e maio e com frutos em dezembro. 


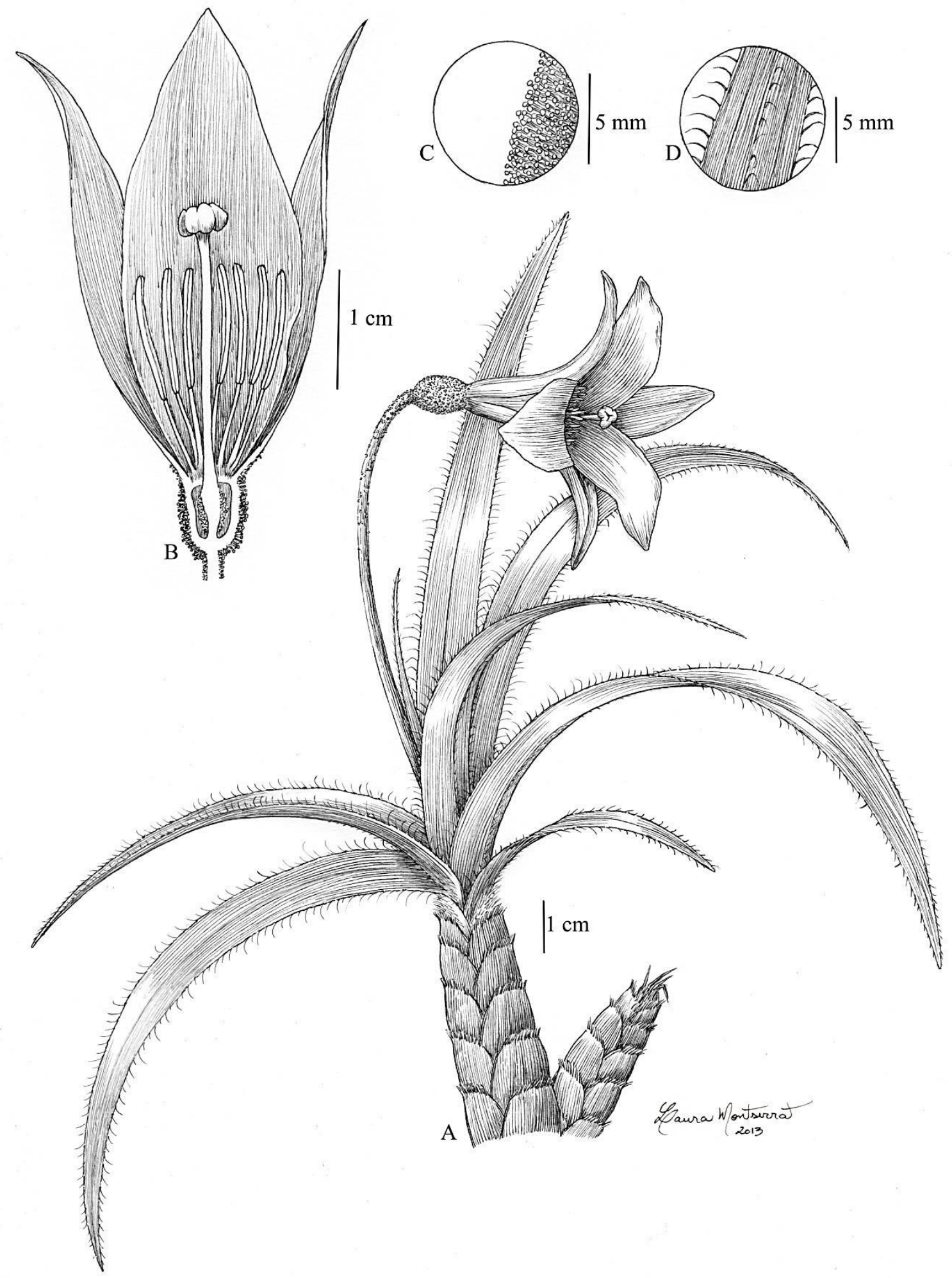

Fig. 3 - Vellozia crinita: A. hábito com flor; B. detalhe da flor em corte longitudinal, mostrando duas sépalas e uma pétala em vista frontal, sete estames opostos à pétala e ovário com estilete e estigma; C. detalhe do hipanto, na região do ovário, mostrando emergências glandulares; D. detalhe da face abaxial da lâmina foliar, mostrando tricomas (Mello-Silva 3249). 


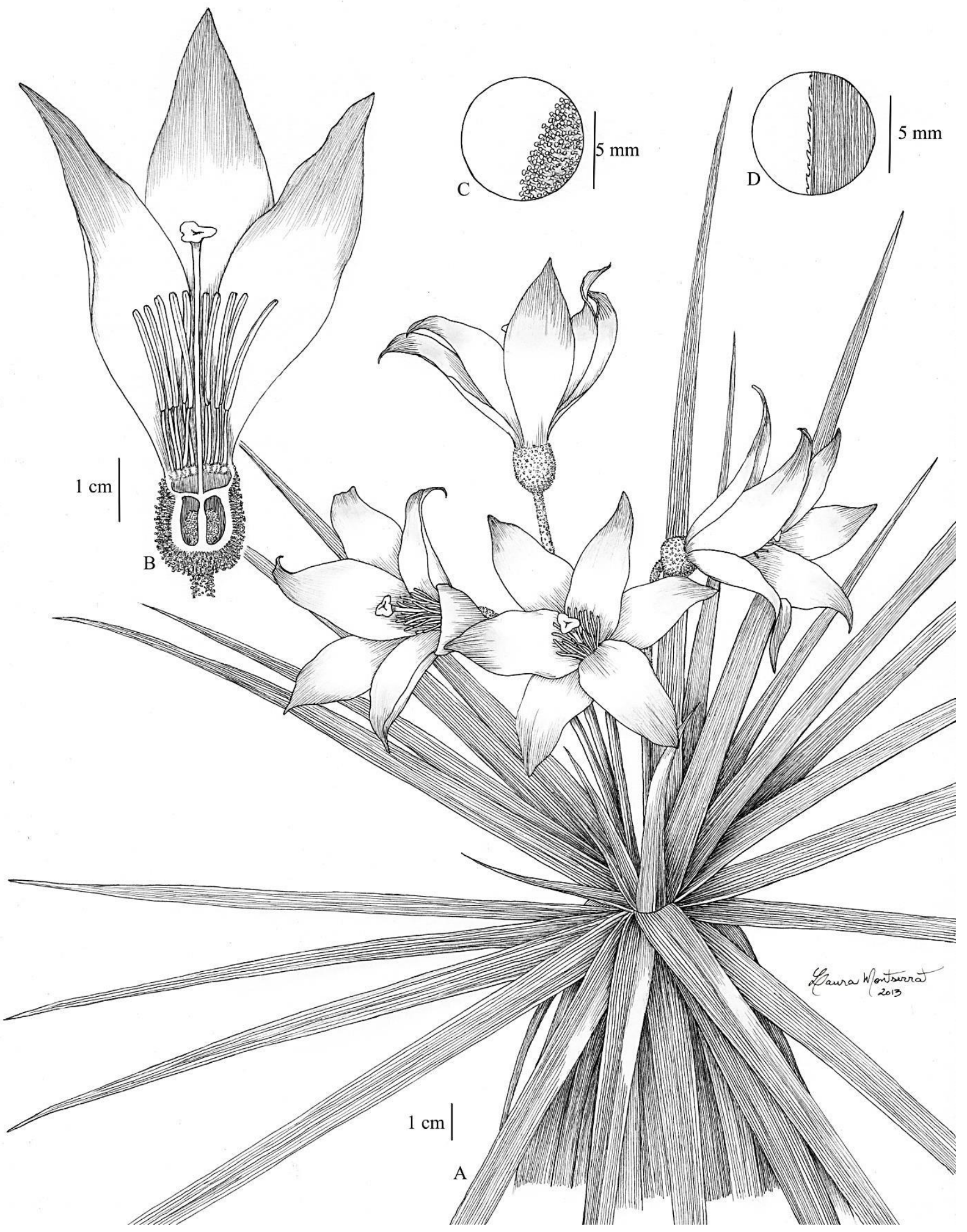

Fig. 4 - Vellozia intermedia: A. hábito com flores; B. detalhe da flor em corte longitudinal, mostrando uma sépala e duas pétalas em vista frontal, dez estames opostos à sépala e ovário com estilete e estigma; C. detalhe do hipanto, na região do ovário, mostrando emergências glandulares; D. detalhe da margem da lâmina foliar, mostrando emergências serreadas (Mello-Silva 3262). 


\section{Agradecimentos}

Os autores agradecem à Fundação de Amparo à Pesquisa do Estado de São Paulo (FAPESP) pela Bolsa de Iniciação Científica de Laura Montserrat, desenvolvida na Universidade de São Paulo (USP) e ao Conselho Nacional de Desenvolvimento Científico e Tecnológico (CNPq) pela Bolsa de Produtividade de Renato de Mello-Silva. Agradecem também ao Instituto Estadual de Florestas de Minas Gerais (IEF) pelo apoio aos trabalhos em Ibitipoca, a Hiroe Sasaki e Rogério Lupo pelas orientações a Laura Montserrat e aos dois pareceristas pela valiosa assessoria.

\section{Referências}

ANDRADE, P.M. \& SOUZA, H.C. 1995. Contribuição ao conhecimento da vegetação do Parque Estadual do Ibitipoca, Lima Duarte, MG. Rev. Árvore 19: 249-261.

CHIAVEGATTO, B. \& BAUMGRATZ, J.F.A. 2007. A família Melastomataceae nas formações campestres do Parque Estadual do Ibitipoca, Minas Gerais, Brasil. Bol. Bot. Univ. São Paulo 25(2): 195-226.

COSTA, C.M.R., HERRMANN, G., MARTINS, C.S., LINS, L.V. \& LAMAS, I.R. 1998. Biodiversidade em Minas Gerais: Um atlas para sua conservação. Fundação Biodiversitas. Belo Horizonte.

DIAS, H.C.T., FILHO, E.I.F., SCHAEFER, C.E.G.R., FONTES, L.E.F \& VENTORIN, L.B. 2002. Geoambientes do Parque Estadual do Ibitipoca, município de Lima Duarte-MG. Rev. Árvore 26(6): 777-786.

FORZZA, R.C., Baumgratz, J.F.A., Bicudo, C.E.M., Canhos, D.A.L., Carvalho, AA., Coelho, M.A.N., Costa, A.F., Costa, D.P., Hopkins, M.G., Leitman, P.M., Lohmann, L.G., Nic Lughadha, E., Maia, L.C., Martinelli, G., Menezes, M., Morim, M.P., Peixoto, A.L., Pirani, J.R., Prado, J., Queiroz, L.P., Souza, S., Souza, V.C., Stehmann, J.R., Sylvestre, L.S., Walter, B.M.T. \& Zappi, D.C. 2012. New Brazilian floristic list highlights conservation challenges. Bioscience 62: 39-45.

LADEIRA, A.S., RIBEIRO, G.A., DIAS, H.C.T., SCHAEFER, C.E.G.R., FILHO, E.F. \& OLIVEIRAFILHO, A.T. 2007. O perfil dos visitantes do Parque Estadual do Ibitipoca (PElb), Lima Duarte, MG. Rev. Árvore 31(6): 1091-1098.

MEDEIROS, E.S.S. \& GUIMARÃES, E.F. 2007. Piperaceae do Parque Estadual do Ibitipoca. Bol. Bot. Univ. São Paulo 25(2): 227-252

MELLO-SILVA, R. 1995a. Aspectos taxonômicos, biogeográficos, morfológicos e biológicos das Velloziaceae de Grão-Mogol, Minas Gerais, Brasil. Bol. Bot. Univ. São Paulo 14:49-79.
MELLO-SILVA, R. 1995b. Velloziaceae. Pp 772-781. In Stannard, B.L. (ed.), Flora of the Pico das Almas, Bahia, Brazil. Royal Botanic Gardens. Kew.

MELLO-SILVA, R. 2005a. Velloziaceae. Pp. 371-376. In Wanderley, M.G.L., Shepherd, G.J. \& Giulietti, A.M. (coord.). Flora Fanerogâmica do Estado de São Paulo. Vol. 4. FAPESP, RiMa. São Paulo.

MELLO-SILVA, R. 2005b. Sistemática atual das monocotiledôneas e trabalhos florísticos brasileiros. 56ํㅡㄹ Congresso Nacional de Botânica. Curitiba. file: ///Resumos/2259.

MELLO-SILVA, R. 2009. Flora de Grão-Mogol, Minas Gerais: Velloziaceae. Bol. Bot. Univ. São Paulo 27(1): 109-118.

MELLO-SILVA, R. 2010. Velloziaceae. Pp. 1666-1672. In Forzza, R.C. et al. (eds.), Catálogo de plantas e fungos do Brasil. Jardim Botânico do Rio de Janeiro. Rio de Janeiro.

MELLO-SILVA, R., SANTOS, D.Y.A.C., SALATINO, M.L.F., MOTTA, L.B., CATTAI, M.B., SASAKI, D., LOVO, J., PITA, P.B., ROCINI, C., RODRIGUES, C.D.N., ZARREI, M. \& CHASE, M.W. 2011. Five vicariant genera from Gondwana: the Velloziaceae as shown by molecules and morphology. Annals of Botany 108: 87-102.

MENINI-NETO, L., ALVES, R.J.V., BARROS, F. \& FORZZA, R.C. 2007. Orchidaceae do Parque Estadual de Ibitipoca, MG, Brasil. Acta Bot. Bras. 21(3): 687-696.

MILWARD-DE-AZEVEDO, M.A. 2007. Passifloraceae do Parque Estadual do lbitipoca, Minas gerais. Bol. Bot. Univ. São Paulo 25(1): 71-79.

MONGUILHOTT, L. \& MELLO-SILVA, R. 2009. Apocynaceae do Parque Estadual de Ibitipoca, Minas Gerais, Brasil. Bol. Bot. Univ. São Paulo 26(2): 93-130. (“2008”).

RODELA, L.G. 2000. Distribuição de campos rupestres e cerrados de altitude na Serra do Ibitipoca, sudeste de Minas Gerais. Dissertação de Mestrado. Universidade de São Paulo. São Paulo.

RODELA, L.G. \& TARIFA, J.R. 2002. O clima na Serra do Ibitipoca, Sudeste de Minas Gerais. GEOUSP Esp. Tempo 11: 101-113.

THIERS, B. 2010 [continuously updated]. Index herbariorum: A global directory of public herbaria and associated staff. New York Botanical Garden's Virtual Herbarium. http://sweetgum.nybg.org/ih/ (Dez 2010).

WANDERLEY, M.G.L., SHEPHERD, G.J. \& GIULIETTI, A.M. (coord.). 2005. Flora Fanerogâmica do Estado de São Paulo. Vol. 4. FAPESP, RiMa. São Paulo. 